\title{
Diagnosis of Mendelian Inherited Disorders in Dogs: Brief Literature Review
}

\author{
Vlad COCOSTÎRC ${ }^{1 *}$, Dana Liana PUSTA ${ }^{1}$ \\ ${ }^{1}$ Faculty of Veterinary Medicine, University of Agricultural Sciences and Veterinary Medicine Cluj-Napoca, \\ Calea Mănăsstur 3-5, 400372, Cluj-Napoca, Romania \\ *corresponding author: vlad.cocostirc@usamvcluj.ro
}

Bulletin UASVM Veterinary Medicine 77(1)/2020

Print ISSN 1843-5270; Electronic ISSN 1843-5378

doi:10.15835/buasvmcn-vm: 2019.0031

\begin{abstract}
Genomic research of hereditary diseases is highly significant in the development of specific diagnostic markers meant to identify dogs carrying gene mutations. The Online Mendelian Inheritance in Animals database shows that there are 324 Mendelian disorders in dogs, of which 247 have their likely causal gene variation identified. The remaining disorders are candidates for future research in dog and human genetics, as it may lead to the description of the causative genomic variants in both species. This paper aims to briefly describe the techniques currently used in the research of dog genetics. Choosing the proper technique is fundamental, as it may differ in accordance to multiple variables such as transmission pattern, number of individuals taken into study and the quality and quantity of the existing information.
\end{abstract}

Keywords: Mendelian inherited diseases, dog, diagnostic methods

\section{Introduction}

According to Online Mendelian Inheritance in Animals (OMIA) database, there are 324 Mendelian disorders in dogs of which 247 have their likely causal gene variation identified (The University of Sydney, 2019). Genomic research provides information on the hereditary character of diseases, furthermore leading to the development of specific diagnostic markers meant to identify dogs carrying gene mutations and selective breeding in order to avoid the emergence of such diseases (Shearin and Ostrander, 2010). In addition, there are multiple diseases in dogs that can serve as genetic model in future research and therapy of human diseases and thus leading to the description of the causative genomic variants in both humans and dogs (Shaffer, 2019). Knowledge regarding the diagnostic methods is mandatory for future research in this specific field of study.

\section{Genome-wide association study}

Single-nucleotide polymorphism (SNP) is the high frequency change of a base pair in the DNA (Genomes Project Consortium, 2010). SNP is used as a marker of a region in the genome. Even though it has a minimum biological impact, its functional implication leads to changes regarding the stability of the messenger RNA transcription, changes of the amino acids and changes in the binding affinity of the transcription factor (Griffith et al., 2008). SNP has two alleles, therefore there are two possible base pair changes in the location of a SNP (Bush and Moore, 2012).

Genome-wide association study (GWAS) identifies the association between the singlenucleotide polymorphism in the entire genome and traits of interest, together with the phenotype (Pearson, 2008). Each sample is analysed by GWAS, and if a variation is identified more frequently in the study group than in the control group, then the 
SNP is considered as associated with the studied trait (Manolio, 2010).

Even though a limited number of markers can be genotyped, the potential of GWAS depends on the level of linkage disequilibrium (Sutter, 2004). Linkage disequilibrium is a specific association of alleles in two or more loci (Slatkin, 2008). In order to analyse genomic associations, the characteristics of linkage disequilibrium of the canine genome must be elucidated. Therefore, given the fact that dog breeds express specific incidence of genetic disorders and phenotypic traits, the identification of linkage disequilibrium through GWAS may lead to the discovery of genes which influences breed specific traits (Ostrander, 2005). More specifically, GWAS can be useful in the identification of multigenic traits (Machiela and Chanock, 2014).

In dogs, GWAS was used in the diagnosis of diseases such as atopic dermatitis (Tengvall et al., 2013), neural tube defect (Safra et al., 2013), degenerative mitral valve disease (Lee $\mathrm{C}$ et al., 2019), hip dysplasia (Bartolomé et al., 2015), glioma (Truvé et al., 2016), cruciate ligament rupture (Baker et al., 2017), cleft lip and palate (Wolf et al., 2015), inflammatory bowel disease (Peiravan et al., 2018) and others.

\section{Exome sequencing}

Exome sequencing is a genomic technique used in order to sequence regions of the genes which code the proteins of the genome (Ng et al., 2009). This technique can be extended to target non-proteic functional coding elements and specific loci (Warr et al., 2015). Exome sequencing can be used as a strategy for discovering rare allele underlying Mendelian phenotypes. Studies of positional cloning targeted on sequences which code proteins were proven to be successful for the identification of monogenic variation. Additionally, most of the alleles which underlie Mendelian disorders destroy sequences which code proteins, and a large part of the rare variation which alter proteins (point mutations and indels) are predicted as having functional consequences (Bamshad et al., 2011). In human medicine research, it is estimated that exome sequencing point out the diagnosis of $30-50 \%$ of the rare Mendelian diseases and it is linked with the patient selection and the disorder type (Frésard and Montgomery, 2018).

Besides human, several species only have a scheme of the genome. Therefore, one must be aware that in the capture structure the responsible genes may be omitted due to the lack of annotation. In such cases, the data can be compensated by the information offered by genes predicted through RNA sequencing. These data can be beneficial for the maximization of the coverage of functional elements in weakly annotated genomes. The often high linkage disequilibrium characteristic to domestic species must be noted, as it may lead to the identification of a benign variant which is in linkage disequilibrium with the causal variant. Thereby, the causal variant may be omitted or may be localized outside the sequencing area. When it comes to the canine specie, the linkage disequilibrium can vary in accordance with the breed (Warr et al., 2015).

In dogs, exome sequencing has been used in the diagnosis of diseases such as progressive retinal atrophy (Reddy et al., 2015), lymphoma (Elvers et al., 2015), glaucoma (Ahram et al, 2015), myotonia congenita (Quitt et al., 2018), lumbosacral stenosis (Mukherjee et al., 2017), hemangiosarcoma (Wang G et al., 2017), osteosarcoma (Sakthikumar et al., 2018), osteoarthritis (Meeson et al., 2019) and others.

\section{Sanger sequencing}

Sanger sequencing is a DNA sequencing method based on the selective integration of dideoxynucleotides through DNA-polymerase during the in vitro replication of DNA (Sanger et al., 1977). The method implies a catalytic enzymatic reaction which polymerizes the complementary DNA fragments to the DNA taken into study. There are two approaches more often used of the Sanger sequencing: the shotgun sequencing and the direct approach (França et al., 2002).

The shotgun sequencing involves sequencing of randomly derived fragments of the entire genome. The order and the orientation of sequences is determined by mapping the individual interpretation up to a reference or by assembling overlapping sequences in larger successive sequences (Meyerson et al., 2010).

The direct approach involves DNA sequencing in sites in which the sequence is already known. The major advantage is represented by the reduced redundancy due to the direct nature of the approach. The direct approach requires the synthesis of each new primer, but this is no longer an issue due to the improvement offered by the primer synthesis technology (França et al., 2002). 
Although the Sanger sequencing has been developed at the end of the 1970's (Sanger et al., 1977), it is still widely used in less extensive researches and in order to validate the results of other types of sequencing.

In the study of canine genetic disorders, the Sanger sequencing has been used in researches of diseases such as spinocerebellar ataxia (Forman et al., 2013), footpad hyperkeratosis (Sayyab et al., 2016), pheochromocytomas and paragangliomas (Korpershoek et al., 2019), pulmonary veno-occlusive disease (Toom et al., 2018), oculocutaneous albinism (Caduff et al., 2017), chondrodystrophy and intervertebral disc disease (Brown et al., 2017) and others.

\section{RNA sequencing}

RNA sequencing offers the possibility to identify most of the RNA types from a cell. It provides between tens and hundreds of millions of interpretations of sequences and information on billions of bases (Ozsolak and Milos, 2010). RNA sequencing is part of the next generation sequencing (NGS) techniques, and it focuses on increasing throughput and decreasing cost. NGS granted the possibility of genome wide investigations involving SNP, alternative splicing, differential expression and epigenetic events (Auer and Doerge, 2010).

RNA sequencing involves the isolation of cellular RNA, fragmentation in random positions and copying into complementary DNA. The fragments which fit in a specific number of bases are kept for amplification through PCR and, subsequently, the complementary DNA is sequenced. The results are aligned next to a reference genome and the number of interpreted sequences is included on the map of each gene of the reference genome (Mortazavi et al., 2008).

Even though RNA sequencing is still a developing technique, it has a series of advantages compared to the other techniques. RNA sequencing is not limited to the identification of transcriptions which correspond to the sequenced genome, unlike the approaches based on hybridization. More specifically, it can reveal the exact location of the transcription limit, up to a single base. Additionally, it can identify sequencing variation (such as SNP) in the transcribed regions (Wang et al., 2009).

RNA sequencing has been used in researches of canine genetic diseases, such as meningioma
(Grenier et al., 2017), invasive urothelial bladder carcinoma (Maeda et al., 2018), mammary gland tumors (Lee $\mathrm{K}$ et al., 2018), malignant melanoma (Hendricks et al., 2018), oligodendrogliomas (Filley et al., 2018), acrodermatitis (Bauer et al., 2018), idiopathic meningoencephalomyelitis (Hoon-Hanks et al., 2018), muscular dystrophy (Brinkmeyer-Langford et al., 2018) and others.

Reverse transcription PCR, Real-time PCR and proteomic studies

Reverse transcription polymerase chain reaction (RT-PCR) allows the analysis of gene expression in a large number of samples and targeting many different genes, while requiring very small amounts of RNA. It involves RNA isolation, complementary DNA synthesis with the help of retroviral enzyme reverse transcriptase and amplification of complementary DNA by polymerase chain reaction. In the end, the amplification products are detected and quantified through real-time polymerase chain reaction (Freeman et al., 1999).

Real-time polymerase chain reaction (qPCR) provides the absolute copy number for a particular target, as other detection methods of RNA such as Northern blot or Southern blot do not offer such a precise quantification. Along with the use in the measurements of gene expression, qPCR may also be used to quantify nucleic acids (Dhanasekaran et al., 2010).

Most of the times, both RT-PCR and qPCR are used hand in hand to obtain a complete result. Even though, RT-PCR can be used by itself for sequencing or for simple detection of RNA, while qPCR may be used for the quantification of copy number of a particular piece of DNA.

The field of proteomics involves the largescale study of structures and functions of proteins, while the proteome refers to the set of expressed proteins of the genetic material of an organism in defined environmental conditions (Ceciliani et al., 2013). Proteomic studies may be used in profiling genetic disorders of dogs, as purebred dogs are inclined to inherited diseases that match various genetic disorders in humans, thus making them important genetic disease models. Also, dogs are commonly used in human cardiovascular research because of their similarity in anatomy and physiology (Bilić et al., 2018).

RT-PCR, qPCR and proteomics come as an aid to confirm and complete the information provided 
by the other genomic techniques, and to discover gene and protein expression.

\section{Conclusions}

Genomic studies have escalated in the last decades, once the canine genome has been sequenced in 2005. Implicitly, studies of Mendelian genetic diseases are of interest due to the possible prevention by identifying the carrier individuals and discharging them from reproduction. The importance of these studies lies also in the possible extrapolation of identified genetic disorders in dogs to humans.

When choosing the proper diagnostic technique in such researches, one must keep in mind a series of factors such as the number of individuals taken into study, transmission pattern and disease type, the quantity of existing information, budget and the expertise of the researchers involved.

Thereby, when it comes to disorders with multigenic ethology, the proper technique would be GWAS because of the complex pathogenesis and transmission mechanism. Regarding oncologic disorders, the more often used techniques are exome sequencing and RNA sequencing, most probably because of the possible implication of proto-oncogenes in the disease mechanism. Also, the current quantity of information regarding the disease taken into study is relevant as in lesser known disorders, de novo sequencing by GWAS and confirmation of the results by Sanger sequencing is necessary.

A more economic approach involves the use of exome sequencing, as it involves lower costs than the rest of the techniques. Another important variable is the need of highly specialized personnel in order to obtain tangible results and to avoid errors.

RT-PCR, qPCR and proteomics provide a deeper insight in the disease mechanisms, gene and protein expression.

Acknowledgments. This research did not receive any specific grant from funding agencies in the public, commercial, or not-for-profit sectors.

\section{References}

1. Ahram D, Grozdanic S, Kecova H, Henkes A, Collin R, Kuehn M (2015). Variants in Nebulin (NEB) Are Linked to the Development of Familial Primary Angle Closure Glaucoma in Basset Hounds. PLOS ONE, 10(5), p.e0126660.

2. Auer P, Doerge R (2010). Statistical Design and Analysis of RNA Sequencing Data. Genetics, 185(2): 405-416.

3. Baker L, Kirkpatrick B, Rosa G, Gianola D, Valente B, Sumner J, Baltzer W, Hao Z, Binversie E, Volstad N, Piazza A, Sample S, Muir P (2017). Genome-wide association analysis in dogs implicates 99 loci as risk variants for anterior cruciate ligament rupture. PLOS ONE, 12(4), e0173810

4. Bamshad M, Ng S, Bigham A, Tabor H, Emond M, Nickerson D, Shendure J (2011). Exome sequencing as a tool for Mendelian disease gene discovery. Nature Reviews Genetics, 12(11): 745-755.

5. Bartolomé N, Segarra S, Artieda M, Francino O, Sánchez E, Szczypiorska M, Casellas J, Tejedor D, Cerdeira J, Martínez A, Velasco A, Sánchez A (2015). A Genetic Predictive Model for Canine Hip Dysplasia: Integration of Genome Wide Association Study (GWAS) and Candidate Gene Approaches. PLOS ONE, 10(4), p.e0122558.

6. Bauer A, Jagannathan V, Högler S, Richter B, McEwan N, Thomas A, Cadieu E, André C, Hytönen M, Lohi H, Welle M, Roosje P, Mellersh C, Casal M, Leeb T (2018). MKLN1 splicing defect in dogs with lethal acrodermatitis. PLOS Genetics, 14(3), p.e1007264.

7. Bilić P, Kuleš J, Galan A, Gomes de Pontes L, Guillemin N, Horvatić A, Festa Sabes A, Mrljak V, Eckersall P (2018). Proteomics in Veterinary Medicine and Animal Science: Neglected Scientific Opportunities with Immediate Impact. Proteomics, 18(14), p.1800047.

8. Brinkmeyer-Langford $\mathrm{C}, \mathrm{Chu} \mathrm{C}$, Balog-Alvarez C, Yu X, Cai J, Nabity M, Kornegay J (2018). Expression profiling of disease progression in canine model of Duchenne muscular dystrophy. PLOS ONE, 13(3), p.e0194485.

9. Brown E, Dickinson P, Mansour T, Sturges B, Aguilar M, Young A, Korff C, Lind J, Ettinger C, Varon S, Pollard R, Brown C, Raudsepp T, Bannasch D (2017). FGF4 retrogene on CFA12 is responsible for chondrodystrophy and intervertebral disc disease in dogs. Proceedings of the National Academy of Sciences, 114(43): 11476-11481.

10. Bush W, Moore J (2012). Chapter 11: Genome-Wide Association Studies. PLoS Computational Biology, 8(12), p.e1002822.

11. Caduff M, Bauer A, Jagannathan V, Leeb T (2017). OCA2 splice site variant in German Spitz dogs with oculocutaneous albinism. PLOS ONE, 12(10), p.e0185944.

12. Ceciliani F, Eckersall D, Burchmore R, Lecchi C (2013). Proteomics in Veterinary Medicine: Applications and Trends in Disease Pathogenesis and Diagnostics. Veterinary Pathology, 51(2): 351-362.

13. Dhanasekaran S, Doherty T, Kenneth J (2010). Comparison of different standards for real-time PCR-based absolute quantification. Journal of Immunological Methods, 354(12): 34-39. 
14. Elvers I, Turner-Maier J, Swofford R, Koltookian M, Johnson J, Stewart C, Zhang C, Schumacher S, Beroukhim R, Rosenberg M, Thomas R, Mauceli E, Getz G, Palma F, Modiano J, Breen M, Lindblad-Toh K, Alföldi J (2015). Exome sequencing of lymphomas from three dog breeds reveals somatic mutation patterns reflecting genetic background. Genome Research, 25(11): 1634-1645.

15. Filley A, Henriquez M, Bhowmik T, Tewari B, Rao X, Wan J, Miller M, Liu Y, Bentley R, Dey M (2018). Immunologic and gene expression profiles of spontaneous canine oligodendrogliomas. Journal of Neuro-Oncology, 137(3): 469-479.

16. Forman O, De Risio L, Mellersh C (2013). Missense Mutation in CAPN1 Is Associated with Spinocerebellar Ataxia in the Parson Russell Terrier Dog Breed. PLoS ONE, 8(5), p.e64627.

17. França L, Carrilho E, Kist T (2002). A review of DNA sequencing techniques. Quarterly Reviews of Biophysics, 35(2): 169-200.

18. Freeman W, Walker S, Vrana K (1999). Quantitative RTPCR: Pitfalls and Potential. BioTechniques, 26(1): 112125.

19. Frésard L, Montgomery S (2018). Diagnosing rare diseases after the exome. Molecular Case Studies, 4(6), p.a003392.

20. Genomes Project Consortium (2010). A map of human genome variation from population-scale sequencing. Nature, 467(7319): 1061-1073.

21. Grenier J, Foureman P, Sloma E, Miller A (2017). RNAseq transcriptome analysis of formalin fixed, paraffinembedded canine meningioma. PLOS ONE, 12(10), p.e0187150.

22. Griffith O, Montgomery S, Bernier B, Chu B, Kasaian K, Aerts S, Mahony S, Sleumer M, Bilenky M, Haeussler M, Griffith M, Gallo S, Giardine B, Hooghe B, Van Loo P, Blanco E, Ticoll A, Lithwick S, Portales-Casamar E, Donaldson I, Robertson G, Wadelius C, De Bleser P, Vlieghe D, Halfon M, Wasserman W, Hardison R, Bergman C, Jones S (2008). ORegAnno: an open-access community-driven resource for regulatory annotation. Nucleic Acids Research, 36: 107-113.

23. Hendricks W, Zismann V, Sivaprakasam K, Legendre C, Poorman K, Tembe W, Perdigones N, Kiefer J, Liang W, DeLuca V, Stark M, Ruhe A, Froman R, Duesbery N, Washington M, Aldrich J, Neff M, Huentelman M, Hayward N, Brown K, Thamm D, Post G, Khanna C, Davis B, Breen M, Sekulic A, Trent J (2018). Somatic inactivating PTPRJ mutations and dysregulated pathways identified in canine malignant melanoma by integrated comparative genomic analysis. PLOS Genetics, 14(9), p.e1007589.

24. Hoon-Hanks L, McGrath S, Tyler K, Owen C, Stenglein $M$ (2018). Metagenomic Investigation of Idiopathic Meningoencephalomyelitis in Dogs. Journal of Veterinary Internal Medicine, 32(1): 324-330.

25. Korpershoek E, Dieduksman D, Grinwis G, Day M, Reusch C, Hilbe M, Fracassi F, Krol N, Uitterlinden A, de Klein A, Eussen B, Stoop H, de Krijger R, Galac S, Dinjens W (2019). Molecular Alterations in Dog Pheochromocytomas and Paragangliomas. Cancers, 11(5): 607.
26. Lee C, Song D, Ro W, Kang M, Park H (2019). Genome-wide association study of degenerative mitral valve disease in Maltese dogs. Journal of Veterinary Science, 20(1), p.63.

27. Lee K, Park H, Son K, Shin T, Cho J (2018). Transcriptome Signatures of Canine Mammary Gland Tumors and Its Comparison to Human Breast Cancers. Cancers, 10(9): 317.

28. Machiela M, Chanock S (2014). GWAS is going to the dogs. Genome Biology, 15(3): 105.

29. Maeda S, Tomiyasu H, Tsuboi M, Inoue A, Ishihara G, Uchikai T, Chambers J, Uchida K, Yonezawa T, Matsuki $N$ (2018). Comprehensive gene expression analysis of canine invasive urothelial bladder carcinoma by RNASeq. BMC Cancer, 18(1).

30. Manolio T (2010). Genomewide Association Studies and Assessment of the Risk of Disease. New England Journal of Medicine, 363(2): 166-176.

31. Meeson R, Todhunter R, Blunn G, Nuki G, Pitsillides A (2019). Spontaneous dog osteoarthritis - a One Medicine vision. Nature Reviews Rheumatology, 15(5): 273-287.

32. Meyerson M, Gabriel S, Getz G (2010). Advances in understanding cancer genomes through secondgeneration sequencing. Nature Reviews Genetics, 11(10): 685-696.

33. Mortazavi A, Williams BA, McCue K, Schaeffer L, Wold B (2008). Mapping and quantifying mammalian transcriptomes by RNA-Seq. Nat Methods, 5(7):621-628.

34. Mukherjee M, Jones J, Yao J (2017). Lumbosacral stenosis in Labrador retriever military working dogs - an exomic exploratory study. Canine Genetics and Epidemiology, 4(1).

35. Ng S, Turner E, Robertson P, Flygare S, Bigham A, Lee C, Shaffer T, Wong M, Bhattacharjee A, Eichler E, Bamshad M, Nickerson D, Shendure J (2009). Targeted capture and massively parallel sequencing of 12 human exomes. Nature, 461(7261): 272-276.

36. Ostrander E (2005). The canine genome. Genome Research, 15(12): 1706-1716.

37. Ozsolak F, Milos P (2010). RNA sequencing: advances, challenges and opportunities. Nature Reviews Genetics, 12(2): 87-98.

38. Pearson $\mathrm{T}$ (2008). How to Interpret a Genome-wide Association Study. JAMA, 299(11), p.1335.

39. Peiravan A, Bertolini F, Rothschild M, Simpson K, Jergens A, Allenspach K, Werling D (2018). Genome-wide association studies of inflammatory bowel disease in German shepherd dogs. PLOS ONE, 13(7), p.e0200685.

40. Quitt P, Hytönen M, Matiasek K, Rosati M, Fischer A, Lohi H (2018). Myotonia congenita in a Labrador Retriever with truncated CLCN1. Neuromuscular Disorders, 28(7): 597605.

41. Reddy B, Kelawala D, Shah T, Patel A, Patil D, Parikh P, Patel N, Parmar N, Mohapatra A, Singh K, Menon R, Pandya D, Jakhesara S, Koringa P, Rao M, Joshi C (2015). Identification of putative SNPs in progressive retinal atrophy affected Canis lupus familiaris using exome sequencing. Mammalian Genome, 26(11-12): 638-649. 
42. Safra N, Bassuk A, Ferguson P, Aguilar M, Coulson R, Thomas N, Hitchens P, Dickinson P, Vernau K, Wolf Z, Bannasch D (2013). Genome-Wide Association Mapping in Dogs Enables Identification of the Homeobox Gene, NKX2-8, as a Genetic Component of Neural Tube Defects in Humans. PLoS Genetics, 9(7), p.e1003646.

43. Sakthikumar S, Elvers I, Kim J, Arendt M, Thomas R, Turner-Maier J, Swofford R, Johnson J, Schumacher S, Alföldi J, Axelsson E, Couto G, Kisseberth W, Pettersson M, Getz G, Meadows J, Modiano J, Breen M, Kierczak M, Forsberg-Nilsson K, Marinescu V, Lindblad-Toh K (2018). SETD2 is recurrently mutated in whole-exome sequenced canine osteosarcoma. Cancer Research, 78(13): 34213431.

44. Sanger F, Nicklen S, Coulson A (1977). DNA sequencing with chain-terminating inhibitors. Proceedings of the National Academy of Sciences, 74(12): 5463-5467.

45. Sayyab S, Viluma A, Bergvall K, Brunberg E, Jagannathan V, Leeb T, Andersson G, Bergström T (2016). WholeGenome Sequencing of a Canine Family Trio Reveals aFAM83G Variant Associated with Hereditary Footpad Hyperkeratosis. G3: Genes, Genomes, Genetics, 6(3): 521527.

46. Shaffer L (2019). Special issue on canine genetics: animal models for human disease and gene therapies, new discoveries for canine inherited diseases, and standards and guidelines for clinical genetic testing for domestic dogs. Human Genetics, 138(5): 437-440.

47. Shearin A, Ostrander E (2010). Leading the way: canine models of genomics and disease. Disease Models \& Mechanisms, 3(1-2): 27-34.

48. Slatkin M (2008). Linkage disequilibrium understanding the evolutionary past and mapping the medical future. Nature Reviews Genetics, 9(6): 477-485.

49. Sutter N (2004). Extensive and breed-specific linkage disequilibrium in Canis familiaris. Genome Research, 14(12): 2388-2396.

50. Tengvall K, Kierczak M, Bergvall K, Olsson M, Frankowiack M, Farias F, Pielberg G, Carlborg Ö, Leeb T, Andersson G,
Hammarström L, Hedhammar Å, Lindblad-Toh K (2013). Genome-Wide Analysis in German Shepherd Dogs Reveals Association of a Locus on CFA 27 with Atopic Dermatitis. PLoS Genetics, 9(5), p.e1003475.

51. The University of Sydney (2019). OMIA - Online Mendelian Inheritance in Animals. Retrieved from https://omia. org/, accessed $14^{\text {th }}$ of June 2019

52. Toom den M, Grinwis G, van Suylen R, Boroffka S, de Jong P, van Steenbeek F, Szatmári V (2018). Pulmonary veno-occlusive disease as a cause of severe pulmonary hypertension in a dog. Acta Veterinaria Scandinavica, 60(1).

53. Truvé K, Dickinson P, Xiong A, York D, Jayashankar K, Pielberg G, Koltookian M, Murén E, Fuxelius H, Weishaupt H, Swartling F, Andersson G, Hedhammar Å, BongcamRudloff E, Forsberg-Nilsson K, Bannasch D, Lindblad-Toh K (2016). Utilizing the Dog Genome in the Search for Novel Candidate Genes Involved in Glioma DevelopmentGenome Wide Association Mapping followed by Targeted Massive Parallel Sequencing Identifies a Strongly Associated Locus. PLOS Genetics, 12(5), p.e1006000.

54. Wang G, Wu M, Maloneyhuss M, Wojcik J, Durham A, Mason N, Roth D (2017). Actionable mutations in canine hemangiosarcoma. PLOS ONE, 12(11), p.e0188667.

55. Wang Z, Gerstein M, Snyder M (2009). RNA-Seq: a revolutionary tool for transcriptomics. Nature Reviews Genetics, 10(1): 57-63.

56. Warr A, Robert C, Hume D, Archibald A, Deeb N, Watson M (2015). Exome Sequencing: Current and Future Perspectives. G3: Genes, Genomes, Genetics, 5(8): 15431550.

57. Wolf Z, Brand H, Shaffer J, Leslie E, Arzi B, Willet C, Cox T, McHenry T, Narayan N, Feingold E, Wang X, Sliskovic S, Karmi N, Safra N, Sanchez C, Deleyiannis F, Murray J, Wade C, Marazita M, Bannasch D (2015). GenomeWide Association Studies in Dogs and Humans Identify ADAMTS20 as a Risk Variant for Cleft Lip and Palate. PLOS Genetics, 11(3), p.e1005059. 